\title{
BMJ Open Disability status and multi-dimensional personal well-being among adolescents in the Southern Highlands Region of Tanzania: results of a cross- sectional study
}

\author{
Sarah Quinones (D) ,' Tia M Palermo (D) ,' Tumpe Mnyawami Lukongo, ${ }^{2}$ \\ Paul Luchemba, ${ }^{3}$ Respichius Mitti, ${ }^{4}$ Karen Devries (1) , ${ }^{5}$ Richard de Groot, ${ }^{6}$ \\ Atif Khurshid, ${ }^{7}$ Hannah Kuper (1) , ${ }^{8}$ on behalf of the Tanzania Adolescent Cash Plus \\ Evaluation Team
}

To cite: Quinones S,

Palermo TM, Lukongo TM, et al. Disability status and multidimensional personal well-being among adolescents in the Southern Highlands Region of Tanzania: results of a crosssectional study. BMJ Open 2021;11:e044077. doi:10.1136/ bmjopen-2020-044077

- Prepublication history and supplemental material for this paper is available online. To view these files, please visit the journal online (http://dx.doi org/10.1136/bmjopen-2020044077).

Received 21 August 2020 Revised 07 December 2020 Accepted 18 March 2021

Check for updates

(c) Author(s) (or their employer(s)) 2021. Re-use permitted under CC BY-NC. No commercial re-use. See rights and permissions. Published by BMJ.

For numbered affiliations see end of article.

Correspondence to Dr Tia M Palermo; tiapaler@buffalo.edu

\section{ABSTRACT}

Objective Examine how disability status among adolescents is associated with the following domains of personal well-being: schooling, livelihoods, health, violence and psychosocial well-being. It is hypothesised that adolescents with a disability will have greater deficits in these areas of well-being compared with their healthier counterparts.

Design Cross-sectional data from 2018 were obtained from the second round of an on-going study of adolescents living in poor households in two regions of the Southern Highlands of Tanzania (Iringa and Mbeya). We use the Washington Group (WG) Short Set indicators to measure disability and undertook logistic and linear multivariate regressions to understand the association between disability and the outcomes of interest.

Participants The sample included 2274 participants aged 15-20 years living in households participating in a government social protection programme targeted to households living in extreme poverty.

Results Overall, 310 participants (14\%) were classified as having disabilities. Outcomes not associated with disability status included literacy, schooling, livelihoods and self-efficacy. Adolescents with disabilities were less likely to report good or very good health (adjusted $\mathrm{OR}$ $(\mathrm{aOR})=0.39,95 \% \mathrm{Cl} 0.29$ to 0.52$)$ and had increased odds of reporting depressive symptoms in (aOR=1.46,95\% Cl 1.11 to 1.90 ), emotional violence ( $\mathrm{aOR}=2.18,95 \% \mathrm{Cl} 1.49$ to 3.20 ) and physical violence $(\mathrm{aOR}=1.71,95 \% \mathrm{Cl} 1.13$ to 2.59), compared with those without disabilities. Reports of depression were higher among men, and violence was more prevalent among women. Patterns of association were generally similar between men and women, although the association of disability with markers of well-being reached statistical significance more often among men. Conclusion This study highlights areas where adolescents with disabilities are falling behind their peers in terms of personal well-being. These findings suggest that interventions may be needed to mainstream disability in programmes and policies aiming to improve well-being, mental health and violence prevention among adolescents.
Strengths and limitations of this study

- The study contributes to evidence on an important gap in understanding of the needs and experiences of adolescents with disabilities from low- and middle-income countries (LMICs).

- The sample for this study was relatively large, particularly for a study focusing on adolescence and disability in Africa.

- Detailed data were collected across various domains of well-being, including schooling, livelihoods, health, violence and psychosocial well-being using standardised and validated scales.

- Power was limited to detect patterns by gender or type of functional difficulty.

- Participants were selected from poor households, and so were not representative of all adolescents in the study area or Tanzania more broadly.

Trial registration number Pan African Clinical Trial Registry (PACTR201804003008116).

\section{INTRODUCTION}

There are more than 1 billion people with disabilities globally, equating to $15 \%$ of the world's population. ${ }^{1}$ People with disabilities face large inequities across different aspects of well-being, such as material well-being (eg, poverty, livelihood), personal well-being (eg, education, health, safety) and community well-being (eg, social inclusion) ${ }^{2}$ These disparities are a violation of their rights, as set out in the UN Convention on the Rights of Persons with Disabilities. Despite progress made in recent years, ${ }^{3}$ we may also fail to achieve the sustainable development goals if they continue to be left behind in key development targets, such as education, 
health and poverty reduction, and so urgent action to promote inclusion and well-being is required. ${ }^{3}$ Disability is, of course, not a homogenous category, and this group includes people with different types of impairment, men and women, inhabitants of different parts of the globe and so on. These characteristics will influence the experience and impacts of living with a disability, and the optimal strategies to promote inclusion. One important factor is age, and a particularly vulnerable group may be adolescents with disabilities.

Awareness of both the importance of adolescence, and the neglect of this group in public health, has grown in recent decades. There are approximately 1.2 billion adolescents aged 10-19 years globally, or 1 in 6 of the world's population. ${ }^{4}$ In sub-Saharan Africa, adolescents comprise $23 \%$ of the population ${ }^{5}$ and in Tanzania specifically, they comprise $24 \%$ of the population. It is now clear that adolescence is a key life stage when health behaviours and educational achievements are established, which influence lifelong socioeconomic status, health and wellbeing. ${ }^{6}$ Consequently, the WHO and other international organisations are giving increasing focus to this period of life as part of development strategies. Adolescents with disabilities are an important and large component of this group. The World Report on Disability does not provide an estimate of the prevalence of disability for adolescents. However, a recent analysis using the Global Burden of Disease data estimated that $14 \%$ of adolescents aged 15-19 years in sub-Saharan Africa had one of four leading causes of disability: intellectual disability, vision or hearing loss, or childhood epilepsy. ${ }^{7}$ This estimated prevalence of disability for adolescents is likely to be imprecise, as on the one hand many conditions are not considered (eg, physical impairments) leading to underestimation, yet on the other hand there may be overestimation of the prevalence as the presence of these conditions does not equate to disability, particularly if well controlled (eg, epilepsy). Compared with their peers without disabilities, adolescents with disabilities are more likely to be excluded from school, ${ }^{38}$ are more vulnerable to having violence perpetrated against them, ${ }^{9-12}$ are excluded from sexual and reproductive health services, ${ }^{312}$ and social interactions, ${ }^{13}$ such as being in a relationship, ${ }^{14} 15$ and face high levels of stigma. ${ }^{14}$ Adolescents with disabilities in low- and middleincome countries (LMICs) are potentially particularly vulnerable to exclusion, as they have diminished access to health care,${ }^{16}$ less financial resources at their disposal and greater social barriers including stigma when compared with high-income country populations. However, data on the needs and experiences of adolescents with disabilities are relatively limited from LMICs, and this group has received little attention, or investment, from development actors. ${ }^{17} 18$

In this paper, we examine how disability is associated with personal well-being across the following domains: schooling, livelihoods, violence and psychosocial wellbeing within a cohort of adolescents from poor communities in Tanzania. We hypothesise that adolescents with disabilities will fall behind their peers without disabilities in these domains, and that women with disabilities may be particularly disadvantaged as they face multiple layers of discrimination.

\section{METHODS}

\section{Study location}

This study was undertaken in the Mbeya and Iringa regions in Southern Tanzania, which are characterised by mountainous terrain and a cool, wet climate. Individuals in these regions face economic and health-related challenges. The percentage of the population age 6 years and older with no education in Iringa is $22 \%$ among women and $15 \%$ among men, while in Mbeya the percentages are $19 \%$ and $13 \%$ among women and men, respectively. ${ }^{19}$ Both men and women in these regions are predominantly employed in agriculture, a sector highly susceptible to economic shocks. ${ }^{20}{ }^{21}$ Only $10 \%$ of the population is covered by any form of health insurance. ${ }^{19}$ Adolescent childbearing is common; among women aged 15-19 years old, 33\% in Mbeya and 20\% in Iringa have started childbearing. ${ }^{22}$

\section{Sample}

This study uses data from the second round (round 2) of data collection (collected May-July 2018) from the evaluation of the Ujana Salama ('Safe Youth' in Swahili) Cash Plus Model for Safe Transitions To A Healthy And Productive Adulthood conducted by the UNICEF Office of Research-Innocenti, University at Buffalo (SUNY), and EDI Group, in collaboration with the Tanzania Social Action Fund, Tanzania Commission for AIDS (TACAIDS) and UNICEF Tanzania.

Data come from 130 villages (65 treatment and 65 control) in two districts in Iringa (Mufindi and Mafinga) and two in Mbeya (Rungwe and Busokelo). Eligibility criteria for the overall evaluation include: (1) being between the ages of 14-19 years (men and women) at baseline (April-June 2017) and (2) living in impoverished, rural households that participate in the Productive Social Safety Net Programme (PSSN). The PSSN is the Government of the United Republic of Tanzania's flagship social protection programme, which comprised a bi-monthly cash transfer, livelihoods enhancement support and a public works programme and reached 1 million households in 2015. Households in this sample were enrolled in the PSSN in the same year. All eligible youth were sampled directly in their households, regardless of whether they took up the cash plus intervention or not. The evaluation examines the effectiveness of a complementary 'cash plus' intervention targeted to adolescents in PSSN households comprised livelihoods and life skills training, mentoring and a productive grant, and facilitation of linkages to strengthened government health services. By round 2 data collection (the first round in which information on disability status was collected), participants who participated in the intervention (47\% of the eligible and 
$10 \%$ of the non-eligible, or $29 \%$ of the total study sample) had been exposed to 12 weeks of face-to-face trainings on livelihoods and life skills, but the remaining two components of the intervention had not yet been implemented (ie, a productive grant, and strengthening links to health service). The current analysis is observational and crosssectional (from round 2) including all eligible youths sampled (ie, those who enrolled in the programme and those that did not), and does not examine impacts of the intervention. More detailed information on the impact evaluation's study design and sampling is provided in online supplemental appendix 1.

Enumerator training for data collection took place 7-18 May 2018 in Bukoba, Tanzania, and included detailed sessions on research ethics, gender-based violence and questionnaire modules, as well as field practices and debriefing sessions (team supervisors received additional training 3-5 May). Same-sex enumerators conducted face to face interviews in Swahili with the adolescents in private locations given the sensitive nature of the interview content. Enumerators entered interview data directly into tablets in real time using SurveyBe software.

Informed consent was obtained from all respondents aged 18 years and older and from married adolescents aged 15-17 years (under Tanzanian law, married individuals above the legal age of marriage ( 15 years) are considered able to give consent). For unmarried respondents aged 15-17 years, informed consent was obtained from caregivers or household heads and informed assent was obtained from the adolescents. There were no married adolescents under the age of 15 years in the sample.

A split sample approach was used for administering questionnaire modules on violence victimisation, based on best practices guidance from Violence Against Children surveys. ${ }^{23}$ Violence modules were alternately administered in one village for women and a second village for men. In an effort to protect the safety and confidentiality of respondents, this approach eliminates the possibility that a male perpetrator and a female victim living in the same community are both interviewed. Following WHO guidelines on violence data collection, we provided respondents with anonymised referral information containing contact numbers for district social welfare officers. $^{24}$

\section{Patient and public involvement}

Patients or the public were not involved in the design, conduct, or reporting, or dissemination plans of this research.

\section{Measures}

The primary predictor of interest in this study is disability, measured using the Washington Group (WG) Short Set Questionnaire. ${ }^{25}$ Respondents were asked if they experienced difficulties with any of the following six activities: seeing (even if wearing glasses), hearing (even if wearing a hearing aid), walking or climbing steps, remembering or concentrating, washing all over or dressing, or communicating. Response options included 'no difficulty', 'some difficulty', 'a lot of difficulty' or 'cannot do at all'. Typically, those who report 'a lot of difficulty' or worse, for any of the measures are categorised as having disabilities. However, this relatively young sample of adolescents has low prevalence of disability using the 'a lot' categorisation, so we define disability as reporting at least 'some' in one or more of these categories, as has been done in previous investigations of this age group. ${ }^{10}$

We measured adolescent outcomes across various domains of personal well-being, including schooling, livelihoods, physical and mental health, stress, self-efficacy and violence experiences. Schooling was defined as currently attending ( $=1$ if yes and $=0$ otherwise), currently attending among those who had not yet graduated Form IV ( $=1$ if yes, $=0$ if not attending, coded to missing if completed Form IV or higher); and able to read and write ( $=1$ if yes and $=0$ otherwise). We use Form IV as a relevant cut-off for schooling in the Tanzanian setting, where students must pass entrance exams after standard 7 (primary school) and Form IV (secondary school) to advance. After Form IV, only those planning to attend university would attend an additional 2 years of advanced level. Self-reported health was measured on a scale from 1 to 5, where respondents were asked 'Imagine a scale from 1 to 5 , where 1 indicates very good health status and 5 indicates very bad health status. How would you rate your personal health status?' and our measure was coded $=1$ if adolescents reported 1 or 2 and $=0$ otherwise. Depression was measured using the 20-item Center for Epidemiologic Studies Depression Scale (CES-D), ${ }^{26}$ a cumulative score of depressive symptoms experienced in the past week such as sleeping poorly, feeling unhappy, hopeless, unmotivated, lacking energy to carry out daily functions, trouble concentrating, fearful, easily bothered or feeling lonely. The scale ranges from a minimum of 0 to a maximum of 30 (Cronbach's $\alpha=0.74$ ) and individuals with scores greater than 9 are classified as reporting depressive symptoms. We use a binary measure for depressive symptoms $=1$ if individuals report 10 or more symptoms, and $=0$ otherwise. This is the most commonly used threshold for CES-D and has been used previously with adolescents in sub-Saharan Africa. ${ }^{27}$

Livelihood activities were classified as performing any work ( $=1$ if yes and $=0$ otherwise), paid work outside the household ( $=1$ if yes and $=0$ otherwise) or farm work for the household ( $=1$ if yes and $=0$ otherwise $)$ in the past 7 days. Farm work included agriculture, caring for livestock or fishing activities. Performance of any work was a composite of hours in farm work, paid work or household business related work in the past 7 days.

Self-efficacy was measured using a locus of control index based on a previously implemented index, ${ }^{28} 29$ where respondents were asked to agree on a scale of 1-5 (5 indicating more agreement) with the following statements: (1) it is not always wise for you to plan too far ahead because many things turn out to be a matter of good or bad fortune, (2) your life is determined by your own 
actions, (3) when you get what you want, it is usually the result of your own actions, (4) you feel like what happens in your life is mostly determined by others and (5) getting what you want requires pleasing the influential people. The index was scored by averaging responses to these five items, with a total possible range of 1-5 (Cronbach's $\alpha=0.52$ ). Higher scores correspond to higher self-efficacy.

Self-perceived stress was measured using subscales of the Enhanced Life Distress Index, a cumulative scale measuring distress in the areas of finances, employment, education, hygiene, environment, health, substance abuse, violence, crime, romance, family, friends and pregnancy. ${ }^{30}$ For each of 12 items assessed, response options range from 0 (no distress) to 3 . The scale is created by summing responses from each item and ranges from a score of 0-36, with a higher score indicating more stress. The subscales analysed are as follows: economic and health-related well-being (EHRW; including financial situation, failure of business or farm, education, food and water, health; range 0-15; Cronbach's $\alpha=0.64$ ), risk/security (substance use, violence, theft; range 0-9; Cronbach's $\alpha=0.46$ ) and relationships (partner, family, friends, pregnancy; range 0-12; Cronbach's $\alpha=0.54$ ).

Experiences of emotional, physical and sexual violence in the past 12 months were assessed using an adapted version of questionnaire items used in the WHO multicountry study on women's health and domestic violence, ${ }^{31}$ which draws on the Conflict Tactics Scale. ${ }^{32}$ For the current study, we adapted these items to include any perpetrator (not just intimate partners). Emotional violence in the previous 12 months was defined as having responded affirmatively to any of the following items: someone had insulted or made them feel bad about themselves; or belittled them, called them names or humiliated them in front of other people. Physical violence experience was having experienced the following in the previous 12 months: someone (1) slapped or pushed him/her; (2) hit him/her with a fist; (3) kicked him/her or beat her up; (4) tried to choke him/her or burn him/her on purpose; (5) threatened or attacked him/her with a knife, gun or any other weapon. Sexual violence in the past 12 months was coded as $=1$ if the respondent reported having experienced any of the following: someone (1) touched them in a sexual way without their permission, (2) physically forced them to have sexual intercourse or (3) forced them to perform other sexual acts that they did not wish to perform and was coded $=0$ otherwise.

\section{Statistical analysis}

We analysed those observations with available data for all measures of interest, as the proportion with missing data was low $(5 \%)$. We first summarised characteristics of the sample, pooled and stratified by disability status. We performed bivariate analyses (t-tests for continuous outcomes and $\chi^{2}$ tests for categorical outcomes) to determine whether differences in background characteristics and outcomes of interest varied by disability status. Next, we ran logistic regressions to examine whether disability status was associated with binary outcomes when controlling for confounders. For continuous variable outcomes (stress and self-efficacy), multivariate linear regressions were run. All models were adjusted for age, sex of respondent, household size, sex of household head (female), residence in a large village and living in the Iringa region (relative to living in Mbeya region). We also ran logistic models separately by sex. Finally, to test for effect modification by sex (models not shown), we present $p$ values for coefficients on the interaction between femalexdisability using linear probability models (LPM). LPM was used given issues with interpretation of interaction effects in logistic regression as described in Norton $e t a l .{ }^{33}$ In multivariate regressions, we adjust SEs for clustering at the village-level. All analyses were carried out using STATA V.16. ${ }^{34}$

\section{RESULTS}

Of 2458 adolescents interviewed at baseline, a total of 2104 were re-interviewed at round 2 (when disability questions were asked), and then an additional 286 adolescents were interviewed for the first time at round 2. Thus, the total number of adolescents interviewed at round 2 of the evaluation was 2390. Among these, the analytic sample for the current study includes those with data on all measures of interest $(\mathrm{N}=2274)$. Violence analyses were run on a smaller sample $(\mathrm{N}=1053)$, given the split-sample approach for this module.

Overall, 310 participants reported to have 'some' or more difficulty in at least one domain of the WG Questions and so were classified as having disabilities, giving a prevalence of $14 \%$. Functional difficulties were most commonly reported for seeing $(6 \%)$, and remembering $(4 \%)$, and rarely for the other domains (table 1$)$. Very few people responded having 'a lot of difficulty' or worse in any domain $(<0.8 \%$ for each), and results were broadly similar for men and women.

In the pooled sample, the majority of the sample was men $(55 \%)$ and the average age was 17 years (table 2). Further, $67 \%$ lived in a female-headed household, with an average household size of five people, and there were slightly more individuals living in Iringa (51\%) than Mbeya (49\%). When examining characteristics by disability status, we see that those with a disability were more likely to be women ( $58 \%$ among people with disabilities vs $43 \%$ among those without disabilities; $\mathrm{p}<0.001)$. Among women, those with disabilities were more likely to be living in Mbeya ( $58 \%$ vs $49 \%$; $p=0.03$ ).

Turning to personal well-being outcomes (table 2), we see that those with disabilities are less likely to report good or very good self-reported health, and this was true among both men $(69 \%$ vs $83 \% ; \mathrm{p}<0.01)$ and women $(69 \%$ vs $87 \% ; \mathrm{p}<0.01)$. Men with disabilities reported lower levels of education (65\% vs $76 \%$ achieved standard 7 or higher, $\mathrm{p}=0.01)$. Across the total group, depressive symptoms were more common in men $(33 \%)$ compared with women $(16 \%)$, and were higher in men with disabilities 


\begin{tabular}{|c|c|c|c|}
\hline $\begin{array}{l}\text { Functional } \\
\text { difficulty type }\end{array}$ & $\begin{array}{l}\text { Total } \\
\text { N (\%) }\end{array}$ & $\begin{array}{l}\text { Male } \\
\text { N (\%) }\end{array}$ & $\begin{array}{l}\text { Female } \\
\mathrm{N}(\%)\end{array}$ \\
\hline \multicolumn{4}{|l|}{ Seeing } \\
\hline None & $2140(94)$ & $1189(96)$ & 951 (92) \\
\hline Some & $118(5)$ & $50(4)$ & $68(7)$ \\
\hline A lot/cannot do & $16(0.7)$ & $6(0.5)$ & $10(1)$ \\
\hline \multicolumn{4}{|l|}{ Hearing } \\
\hline None & $2231(98)$ & $1222(98)$ & 1009 (98) \\
\hline Some & $41(2)$ & $22(2)$ & $19(2)$ \\
\hline A lot/cannot do & $2(0.1)$ & $1(0.1)$ & $1(0.1)$ \\
\hline \multicolumn{4}{|l|}{ Walking } \\
\hline None & 2222 (98) & $1224(98)$ & $998(97)$ \\
\hline Some & $48(2)$ & $20(2)$ & $28(3)$ \\
\hline A lot/cannot do & $4(0.2)$ & $1(0.1)$ & $3(0.3)$ \\
\hline \multicolumn{4}{|l|}{ Remembering } \\
\hline None & $2173(96)$ & $1199(96)$ & 974 (95) \\
\hline Some & $93(4)$ & $43(3)$ & $50(5)$ \\
\hline A lot/cannot do & $8(0.4)$ & $3(0.2)$ & $5(0.5)$ \\
\hline \multicolumn{4}{|l|}{ Washing } \\
\hline None & 2249 (99) & $1231(99)$ & 1018 (99) \\
\hline Some & $22(1)$ & $13(1)$ & $9(1)$ \\
\hline A lot/cannot do & $3(0.1)$ & $1(0.1)$ & $2(0.2)$ \\
\hline \multicolumn{4}{|l|}{ Communicating } \\
\hline None & 2241 (99) & 1232 (99) & 1009 (98) \\
\hline Some & $31(1)$ & $11(1)$ & $20(2)$ \\
\hline A lot/cannot do & $2(0.1)$ & $2(0.2)$ & 0 \\
\hline
\end{tabular}

compared with those without $(42 \%$ vs $32 \%, \mathrm{p}=0.02)$. Similarly, among men with disabilities stress related to economic and health-related well-being $(\mathrm{p}<0.01)$ and relationships $(p<0.01)$ were more common than for men without disabilities. By contrast, depression and stress did not differ between women with and without disabilities. The prevalence of violence reports was high, and consistently higher in women than men for sexual violence ( $7 \%$ vs $1 \%)$, physical violence ( $17 \%$ vs $13 \%)$, emotional violence $(32 \%$ vs $22 \%)$ or any violence $(40 \%$ vs $27 \%)$. Reports of emotional or any violence were higher among adolescents with disabilities compared with those without, and this was apparent in both men $(36 \%$ vs $20 \%, \mathrm{p}=0.01$; $43 \%$ vs $25 \%, \mathrm{p}<0.01)$ and women $(46 \%$ vs $29 \%, \mathrm{p}<0.01$; $51 \%$ vs $38 \%, \mathrm{p}=0.03)$. Among men, physical violence was reported more frequently among those with disabilities compared with those without ( $23 \%$ vs $12 \%, \mathrm{p}=0.01$ ) but this difference was not apparent among women. There were no differences by disability status in the following outcomes: schooling (whether measured in terms of attendance, literacy or attendance among those who have not completed Form IV), livelihoods (including any work, paid work, or farm/livestock/fishing work, risk and violence subscale of self-perceived stress, or self-efficacy).

In multivariate regressions, across the total group disability was not associated with literacy, schooling, livelihood or self-efficacy outcomes (table 3). Disaggregating the data by gender, disability was associated with lower odds of attaining standard 7 or higher in men with disabilities compared with those without (adjusted OR $(\mathrm{aOR})=0.64,95 \%$ CI 0.43 to 0.96$)$, but no association with disability was observed in women $(\mathrm{aOR}=1.02,95 \%$ CI 0.63 to 1.63). No other gender differences in the association of disability with school, work and self-efficacy outcomes were detected.

Turning to health, stress and violence outcomes (table 4), adolescents with disabilities had $61 \%$ lower odds of reporting good or very good health $(\mathrm{aOR}=0.39$, $95 \%$ CI 0.29 to 0.52$), 46 \%$ increased odds of reporting depressive symptoms in the past week $(\mathrm{aOR}=1.46,95 \%$ CI 1.11 to 1.90 ) and $88 \%$ increased odds of experiencing any type of violence in the 12 months preceding the interview ( $\mathrm{aOR}=1.88,95 \%$ CI 1.30 to 2.73 ), compared with adolescents without disabilities. Looking at violence type, those with disabilities had increased odds of experiencing emotional violence $(\mathrm{aOR}=2.18,95 \%$ CI 1.49 to $3.20)$ and physical violence $(\mathrm{aOR}=1.71,95 \%$ CI 1.13 to 2.59), compared with those without disabilities. Differences in sexual violence experiences were not statistically significant. Further, adolescents with disabilities reported higher stress related to health and economic-related wellbeing $(\beta=0.79, p<0.01)$ as well as relationships $(\beta=0.22$, $\mathrm{p}<0.01)$ than those without disabilities. There were no significant differences observed between those with and without disabilities on the risk and violence related stress subscales. Disaggregating the results for health, violence and stress outcomes with disability, by gender, we observe that the patterns of association are broadly the same between men and women. Among men, the association of disability with depression, any violence, physical violence, economic and health-related well-being stress and relationship stress were apparent, whereas in women they failed to achieve statistical significance. When testing modification effects, the interaction between women and disability was only statistically significant $(p<0.05)$ for the EHRW-related stress subscale, indicating that disability affects this outcome differently between men and women.

\section{DISCUSSION}

This analysis of cross-sectional data from 2274 adolescents aged 15-20 years from Tanzania found substantial and multi-dimensional differences in personal well-being among adolescents with disabilities compared with their peers without disabilities. Adolescents with disabilities reported worse health and well-being, and higher prevalence of depressive symptoms. They also experienced more physical, emotional and overall violence, and had higher levels of stress related to well-being and relationships. Surprisingly, there was no difference identified in 
Table 2 Descriptive statistics* for adolescents (15-19 years) from round 2-disaggregated by sex

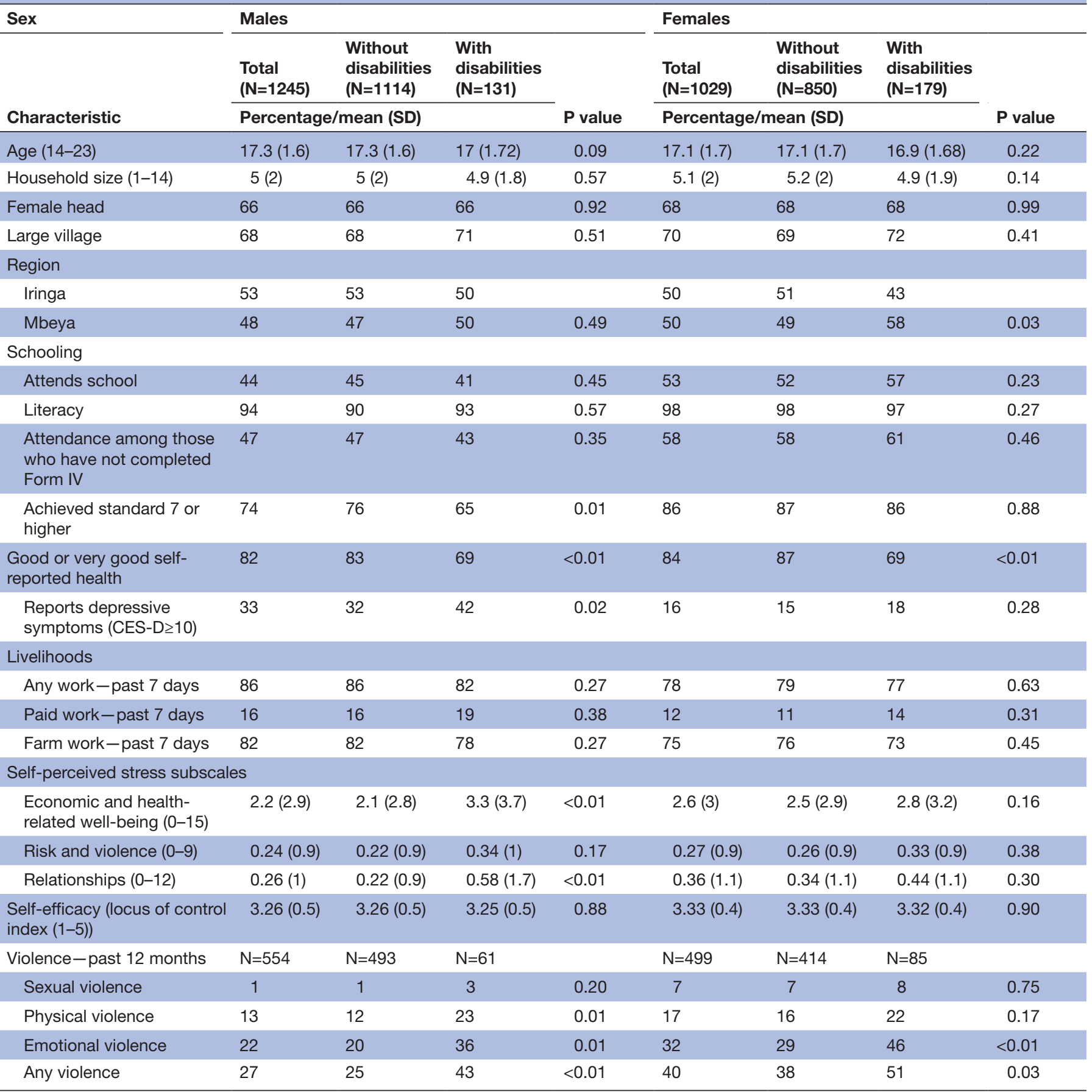

*Mean (SD).

CES-D, Center for Epidemiologic Studies Depression Scale.

schooling measures or livelihood between adolescents with and without disabilities. The higher levels of sexual violence reported by adolescents with disabilities did not reach statistical significance. Patterns were generally similar between men and women, although the association of disability with markers of well-being reached statistical significance more often among men.

Similar to other studies, we found higher levels of reported experiences of violence among adolescents with disabilities, ${ }^{35}$ and this has also been highlighted in the recent UN Flagship report on disability. ${ }^{3}$ There are multiple potential reasons why this might be the case. People with disabilities can face high levels of stigma and higher levels of social isolation relative to their peers without disabilities, which may increase risk of violence. ${ }^{36}$ Attitudes and traditional beliefs about disabilities in communities where adolescents live may also lead to more violence. ${ }^{36}$ Conversely, violence experienced by adolescents in our study may also be a cause of some disability, where exposure to acts of violence leads to new, 


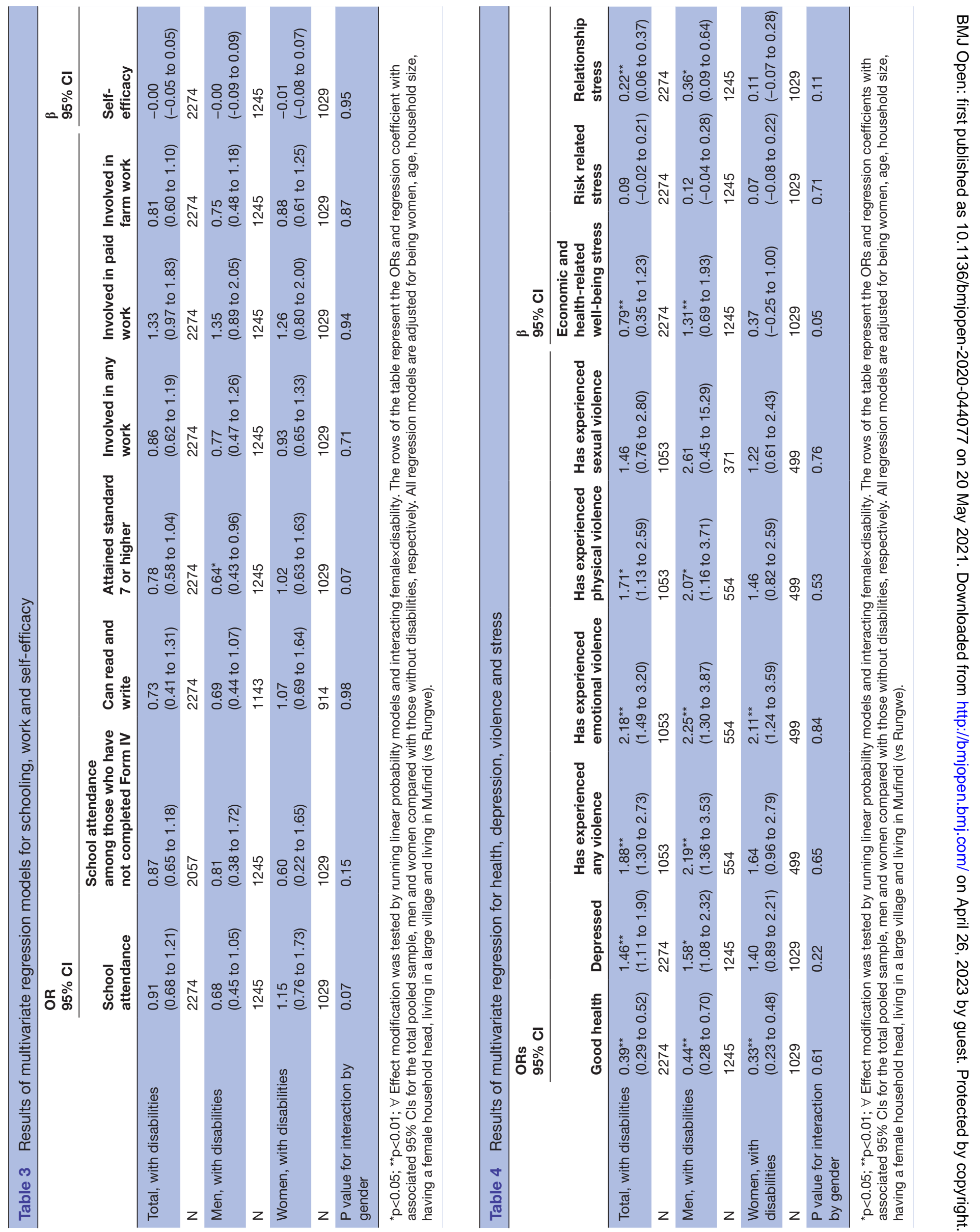


or higher levels, of functional difficulties. The existing literature suggests that women with disabilities are more vulnerable to violence than men with disabilities. Traditional views on gender roles and acceptable gendered behaviour may further exacerbate risk for women, and furthermore some research has also suggested that girls with disabilities may be at particular risk because they are less able to seek help, or defend themselves from those using violence against them. ${ }^{37}$ In our analyses, the prevalence of violence was higher among women, as expected. However, the differences between those with and without disabilities was greater for men than for women, perhaps because of the consistently high levels of violence experienced by all women.

The poorer health, including mental health, experienced by adolescents with disabilities is consistent with the literature of people with disabilities in general. ${ }^{38}{ }^{39}$ There are a number of potential pathways for the association of disability and poor health. In this study, disability was defined as a result of difficulties in functioning using the WG questions (eg, difficulties walking), which are usually the result of an underlying health condition (eg, diabetes) and impairment (eg, amputation). The health condition and/or impairment themselves lead to additional healthcare needs. People with disabilities are also often poorer, and have less access to healthcare, which also contribute to worse health status. Poor mental health may be both a cause and a consequence of disability, hence, explaining the link of depression and disability that we observed. Surprisingly, the reported prevalence of depression was higher among men than women, particularly men with disabilities. Generally, the prevalence of depression is higher in women in adolescents, ${ }^{40}$ including in the sparse data that exists from Africa. ${ }^{41}$ Further, a study among 14 years old in a high-income setting found that women with disabilities also experience particularly high levels of emotional difficulty. ${ }^{42}$ Differences between findings in these existing studies and our own may be attributable to differences in scales used to measure depressive symptoms (use of the Beck Depression Inventory II vs CES-D) or due to differences in study populations, including age composition, poverty status and urban/rural setting.

The lack of difference in educational or livelihood outcomes between adolescents with and without disabilities is surprising, given that the literature generally finds a strong link. ${ }^{39}$ We are unable to conclude with certainty from these data what might explain the lack of differences found in this sample as compared with existing studies, but we have two hypotheses. First, the sample for the current analyses was drawn from the evaluation study of the 'cash plus' intervention, although before most of the intervention components had been delivered. ${ }^{43}$ However, all study households were receiving the PSSN, which included bi-monthly cash transfers, since 2015. PSSN has previously been show to lead to increases in school attendance across all age ranges, grade level attainment and an increase in the ability to read and write. ${ }^{44}$ In addition, that previous study found that the PSSN led to a shift in child labour from paid work outside the household to work within the household. Thus, the PSSN may have addressed some vulnerabilities among adolescents with disabilities. Nevertheless, the previous study did not examine impacts by disability status, so we cannot conclude whether the PSSN essentially helped adolescents with disabilities 'catch up'. A second explanation may relate to the overall vulnerability of all adolescents in the study sample. Because they all come from households receiving the PSSN, they are marginalised and among the poorest $10 \%$ of the population of Tanzania. Thus, this sample is not generalisable to the general population of adolescents in Tanzania or elsewhere, and they may all be facing significant barriers to school attendance and economic participation meaning that the disparities between those with and without a disability are fewer in this population.

There are a number of strengths and limitations which must be taken into account when considering these findings. In this study, disability was defined as having 'some' or more difficulty in at least one of the functional domains, rather than the standard classification as 'a lot of' difficulty or more to provide sufficient sample size for the analysis. Outcome misclassification cannot be dismissed as the Cronbach's alpha values for some of the indices (locus of control, EHRW, risks/security and relationships stress scales) were quite low (0.46-0.64). Moreover, the WG Short Set was used, and so certain functional limitations, in particular those related to mental health, were not included. Consequently, the differences between adolescents with and without disabilities may have been underestimated. Future studies on adolescents may benefit from using the more extensive WG/UNICEF Child Functioning Module, which also includes items on psychological and behavioural conditions. ${ }^{45}$ Data on violence were only available for half the sample, and additionally, there was limited power to detect patterns by gender or type of functional difficulty. The data analysed were cross-sectional, limiting our ability to make inferences on cause and effect. Furthermore, participants were selected from poor households, and so were not representative of the district, let alone of Tanzania more broadly. In terms of strengths, this was a relatively large sample, particularly for a study focusing on adolescence and disability in Africa. Furthermore, multidimensional measures of personal well-being were taken, using standardised and validated scales.

\section{CONCLUSION}

Adolescents with disabilities are still left behind in terms of personal well-being measures even within a very poor community. Interventions may be needed to mainstream disability in programmes and policies aiming to improve well-being, mental health and violence prevention. Adolescents with disabilities continue to be left behind, and so social protection programmes and other development interventions may need to include a particular 
focus on disability in order to improve well-being, mental health and violence prevention. This could include offering additional focus or benefits to those with disabilities, providing training to programme managers to ensure that they effectively including people with disabilities or implementing media campaigns to promote disability equality.

\section{Author affiliations}

${ }^{1}$ Epidemiology and Environmental Health, State University of New York at Buffalo, Buffalo, New York, USA

${ }^{2}$ Research and Development Unit, Tanzania Social Action Fund, Dodoma, United Republic of Tanzania

${ }^{3}$ Monitoring and Evaluation Unit, Tanzania Social Action Fund, Dodoma, United Republic of Tanzania

${ }^{4}$ EDI Global, Bukoba, United Republic of Tanzania

${ }^{5}$ Department of Global Health and Development, London School of Hygiene \&

Tropical Medicine, London, UK

${ }^{6}$ Independent Consultant, Amsterdam, The Netherlands

${ }^{7}$ UNICEF, New York City, New York, USA

${ }^{8}$ International Centre for Evidence in Disability, Clinical Research Department, London School of Hygiene \& Tropical Medicine, London, UK

\section{Twitter Tia M Palermo @tiapalermo}

Acknowledgements The authors would like to acknowledge the support of the TASAF and TACAIDS, in particular Ladislaus Mwamanga (TASAF), Amadeus Kamagenge (TASAF) and Mishael Fariji (TASAF) for the implementation of this evaluation. In addition, the UNICEF personnel instrumental to the initial planning stages of this pilot and study include: Beatrice Targa, Patricia Lim Ah Ken, Victoria Chuwa, Naomi Neijhoft and Tulanoga Matwimbi. We would also like to acknowledge the hard-working field teams of EDI Group, who conducted the data collection for this study to the highest professional standards.

Collaborators Evaluation Team: University at Buffalo: Tia Palermo (co-Principal Investigator); UNICEF Office of Research: Valeria Groppo, Jacobus de Hoop, Lusajo Kajula (Qualitative co-Principal Investigator), Leah Prencipe, Jennifer Waidler Heisecke; EDI Global: Johanna Choumert Nkolo (co-Principal Investigator), Respichius Mitti (co-Principal Investigator), Bhoke Munanka; TASAF: Paul Luchemba, Tumpe Mnyawami Lukongo; TACAIDS: Aroldia Mulokozi; UNICEF Tanzania: Ulrike Gilbert, Paul Quarles van Ufford, Rikke Le Kirkegaard, Frank Eetaama

Contributors TMP, HK and KD conceptualised the topic for this manuscript. TMP, TML, PL and RM were responsible for the research design. SQ and TMP conducted the statistical analysis. SQ, TMP, HK and KD wrote the first draft of the manuscript. SQ, TMP, TML, PL, RM, KD, AK, HK, RdG contributed to interpretation of statistical analyses, revising writing the manuscript and approved the final version. Members of the evaluation team further contributed to study design and data collection.

Funding Funding for the Tanzania Adolescent Cash Plus (Ujana Salama) evaluation has been provided by Oak Foundation (\#OCAY-16-73) and UNICEF Tanzania; as well as the Swedish Development Cooperation (G41102) and the UK Department for International Development (203529-102) through grants to UNICEF Office of Research—Innocenti supporting the Transfer Project. Additional funding for implementation of programprogramme activities was provided by Irish Aid. Additional support for writing of this manuscript was provided to Hannah Kuper by the PENDA grant from the UK Department for International Development. The funders had no role in analysis or interpretation of data.

Competing interests All authors have completed the ICMJE uniform disclosure form at www.icmje.org/coi_disclosure.pdf and declare: support for writing of this manuscript was provided to HK by the UK Department for International Development; PL and TML are paid staff at the government agency (TASAF) which implemented the intervention being evaluated in the larger Adolescent Cash Plus Study from which data for the current manuscript were drawn; AK is paid staff (and TMP was paid staff during the period of data collection in 2018) at UNICEF which provided technical support for implementation of the aforementioned intervention; no financial relationships with any organisations that might have an interest in the submitted work in the previous 3 years; no other relationships or activities that could appear to have influenced the submitted work.

Patient consent for publication Not required.
Ethics approval Ethics approval for the study was granted by the National Institute for Medical Research (NIMR/HQ/R.8a/Vol.IX/2784) and the Tanzania Commission for Science and Technology (COSTECH).

Provenance and peer review Not commissioned; externally peer reviewed.

Data availability statement No data are available. Data may be made public subject to Government and UNICEF approval, no sooner than one year after publication of the final impact evaluation report.

Supplemental material This content has been supplied by the author(s). It has not been vetted by BMJ Publishing Group Limited (BMJ) and may not have been peer-reviewed. Any opinions or recommendations discussed are solely those of the author(s) and are not endorsed by BMJ. BMJ disclaims all liability and responsibility arising from any reliance placed on the content. Where the content includes any translated material, BMJ does not warrant the accuracy and reliability of the translations (including but not limited to local regulations, clinical guidelines, terminology, drug names and drug dosages), and is not responsible for any error and/or omissions arising from translation and adaptation or otherwise.

Open access This is an open access article distributed in accordance with the Creative Commons Attribution Non Commercial (CC BY-NC 4.0) license, which permits others to distribute, remix, adapt, build upon this work non-commercially, and license their derivative works on different terms, provided the original work is properly cited, appropriate credit is given, any changes made indicated, and the use is non-commercial. See: http://creativecommons.org/licenses/by-nc/4.0/.

\section{ORCID iDs}

Sarah Quinones http://orcid.org/0000-0001-8869-856X

Tia M Palermo http://orcid.org/0000-0003-0419-2049

Karen Devries http://orcid.org/0000-0001-8935-2181

Hannah Kuper http://orcid.org/0000-0002-8952-0023

\section{REFERENCES}

1 World Health Organization. World report on disability World Health Organization [and] The World Bank. Geneva, Switzerland, 2011.

2 OECD. OECD Regional Well-Being: A user's guide. Paris: Organisation for EConomic Co-operation and Development (OECD), 2018.

3 Nations U. Disability and development report: Realizing the sustainable development goals by, for and with persons with disabilities New York. UN, 2018.

4 WHO. Adolescents: health risks and solutions Geneva: World Health organization, 2018. Available: https://www.who.int/news-room/factsheets/detail/adolescents-health-risks-and-solutions [Accessed 13 Jul 2020].

5 UNICEF. Adolescent demographics, 2019. Available: https://data. unicef.org/topic/adolescents/demographics/November

6 Sheehan P, Sweeny K, Rasmussen B, et al. Building the foundations for sustainable development: a case for global investment in the capabilities of adolescents. Lancet 2017:390:1792-806.

7 Olusanya BO, Wright SM, Nair MKC, et al. Global burden of childhood epilepsy, intellectual disability, and sensory impairments. Pediatrics 2020;146. doi:10.1542/peds.2019-2623. [Epub ahead of print: 17 Jun 2020].

8 Kuper H, Monteath-van Dok A, Wing K, et al. The impact of disability on the lives of children; cross-sectional data including 8,900 children with disabilities and 898,834 children without disabilities across 30 countries. PLoS One 2014;9:e107300.

9 Devries KM, Kyegombe N, Zuurmond M, et al. Violence against primary school children with disabilities in Uganda: a cross-sectional study. BMC Public Health 2014;14:1017.

10 Devries K, Kuper H, Knight L, et al. Reducing physical violence toward primary school students with disabilities. J Adolesc Health 2018;62:303-10.

11 Banks LM, Kelly SA, Kyegombe N, et al. "If he could speak, he would be able to point out who does those things to him": Experiences of violence and access to child protection among children with disabilities in Uganda and Malawi. PLoS One 2017;12:e0183736.

12 Burke E, Kébé F, Flink I, et al. A qualitative study to explore the barriers and enablers for young people with disabilities to access sexual and reproductive health services in Senegal. Reprod Health Matters 2017;25:43-54.

13 Rukuni R, McHugh G, Majonga E, et al. Disability, social functioning and school inclusion among older children and adolescents living with HIV in Zimbabwe. Trop Med Int Health 2018;23:149-55. 
14 Goodall J, Salem S, Walker RW, et al. Stigma and functional disability in relation to marriage and employment in young people with epilepsy in rural Tanzania. Seizure 2018;54:27-32.

15 Hunt X, Swartz L, Carew MT, et al. Dating persons with physical disabilities: the perceptions of South Africans without disabilities. Cult Health Sex 2018;20:141-55.

16 Homer CSE, Castro Lopes S, Nove A, et al. Barriers to and strategies for addressing the availability, accessibility, acceptability and quality of the sexual, reproductive, maternal, newborn and adolescent health workforce: addressing the post-2015 agenda. BMC Pregnancy Childbirth 2018;18:55.

17 Mitra S, Posarac A, Vick B. Disability and poverty in developing countries: a multidimensional study. World Dev 2013;41:1-18.

18 Banks LM, Kuper H, Polack S. Poverty and disability in lowand middle-income countries: a systematic review. PLoS One 2017;12:e0189996.

19 MoHCDGEC, MoH, NBS, OCGS, and ICF. Ministry of Health CD, Gender, Elderly, Children - MoHCDGEC/Tanzania Mainland, Ministry of Health - MoH/Zanzibar, et al. Tanzania Demographic and Health Survey and Malaria Indicator Survey 2015-2016. Dar es Salaam, Tanzania, 2016

20 Derbile EK, File DJM, Dongzagla A. The double tragedy of agriculture vulnerability to climate variability in Africa: how vulnerable is smallholder agriculture to rainfall variability in Ghana? Jamba 2016;8:249.

21 Lawlor K, Handa S, Seidenfeld D, et al. Cash transfers enable households to cope with agricultural production and price shocks: evidence from Zambia. J Dev Stud 2019;55:209-26.

22 MoHCDGEC, MoH, NBS, OCGS, and ICF. Ministry of Health CD, Gender, Elderly and Children [Dar es Salaam];, Ministry of Health [Zanzibar], National Bureau of Statistics [Dar es Salaam], et al. Tanzania Demographic and Health Survey and Malaria Indicator Survey 2015-2016. Dar es Salaam, Tanzania and Rockville, MD, USA, 2016.

23 UNICEF Tanzania. Centers for disease control and prevention, Muhimbili University of health and allied sciences. violence against children in Tanzania: findings from a national survey, 2009. summary report on the prevalence of sexual, physical and emotional violence, context of sexual violence, and health and behavioural consequences of violence experienced in childhood. Dar es Salaam, Tanzania: UNICEF Tanzania, 2011

24 Organization WH. Researching violence against women: practical guidelines for researchers and activists. World Health Organization, 2005.

25 Statistics WGoD. Short set of disability questions New York: Washington group on disability statistics, United national statistical Commission, 2016. Available: http://www.washingtongroup-disability. $\mathrm{com} /$ washington-group-question-sets/short-set-of-disabilityquestions/ [Accessed 13 Jul 2020]

26 Radloff LS. The CES-D scale: a self-report depression scale for research in the general population. Appl Psychol Meas 1977;1:385-401.

27 Kilburn K, Prencipe L, Hjelm L, et al. Examination of performance of the center for epidemiologic studies depression scale short form 10 among African youth in poor, rural households. BMC Psychiatry 2018;18:201.
28 Levenson H. Differentiating among internality, powerful others, and chance. research with the locus of control construct. 1981: 1, 15-63.

29 Laajaj R, Macours K. Measuring skills in developing countries. The World Bank, 2017

30 Palermo T, Hall BJ, Cirillo C, et al. Enhanced life distress inventory: development and validation in two African countries. $\mathrm{Br} \mathrm{J}$ Health Psychol. In Press 2020;25:728-53.

31 Garcia-Moreno C, Jansen HAFM, Ellsberg M, et al. Prevalence of intimate partner violence: findings from the who multicountry study on women's health and domestic violence. Lancet 2006;368:1260-9.

32 Straus MA, Hamby SL, Boney-McCoy S. The revised conflict tactics scales (CTS2) development and preliminary psychometric data. $J$ Fam Issues 1996:17:283-316.

33 Norton EC, Wang $\mathrm{H}, \mathrm{Ai}$ C. Computing interaction effects and standard errors in logit and probit models. Stata J 2004;4:154-67.

34 StataCorp LLC. Stata Statistical Software: Release 16. [program. College Station, TX, 2019.

35 Jones L, Bellis MA, Wood S, et al. Prevalence and risk of violence against children with disabilities: a systematic review and metaanalysis of observational studies. Lancet 2012;380:899-907.

36 Committee on the Rights of the Child. Committee on the Rights of the Child, General Comment No. 9, The rights of children with disabilities (Forty-third session, 2007). In: Committee on the rights of the child. UN Doc CRC/C/GC/9, 2007.

37 Rousso H. Education for all: a gender and disability perspective. background paper prepared for the education for all global monitoring report 2003/4: gender and education for all: the leap the equality. Paris: UNESCO, 2003.

38 World Health Organization. World report on disability 2011: World Health organization, 2011.

39 Kuper H, Heydt P. The missing billion: access to health services for 1 billion people with disabilities. London and Geneva: London School of Hygiene and Tropical Medicine and World Health Organization, 2019.

40 Bulhões C, Ramos E, Severo M, et al. Measuring depressive symptoms during adolescence: what is the role of gender? Epidemiol Psychiatr Sci 2019;28:66-76.

41 Nduna M, Jewkes RK, Dunkle KL, et al. Prevalence and factors associated with depressive symptoms among young women and men in the eastern Cape Province, South Africa. $J$ Child Adolesc Ment Health 2013;25:43-54.

42 Emerson E, King T, Llewellyn G, et al. Emotional difficulties and selfharm among British adolescents with and without disabilities: cross sectional study. Disabil Health J 2019;12:581-7.

43 Tanzania Cash Plus Evaluation Team. A cash plus model for safe transitions to a healthy and productive adulthood: midline report. Florence, Italy: UNICEF Office of Research - Innocenti, 2020.

44 De Hoop J, Gichane MW, Groppo V. Cash transfers, public works and child activities: mixed methods evidence from the United Republic of Tanzania. Office of Research - Innocenti Working Paper Series, 2020.

45 WG/UNICEF. WG/UNICEF child functioning module (CFM): the Washington group; 2020, 2020. Available: https://www. washingtongroup-disability.com/question-sets/wgunicef-childfunctioning-module-cfm/December 